\title{
The Brain Metabolic Signature in Superagers Using In Vivo 'H-MRS: A Pilot Study
}

(D) L.L. de Godoy, (D)A. Studart-Neto, (D) M. Wylezinska-Arridge, (DM.H. Tsunemi, (D) N.C. Moraes, (D) M.S. Yassuda, (D) A.M. Coutinho, (D) C.A. Buchpiguel, (D) R. Nitrini, (D). Bisdas, and (D). da Costa Leite

\begin{abstract}
BACKGROUND AND PURPOSE: Youthful memory performance in older adults may reflect an underlying resilience to the conventional pathways of aging. Subjects having this unusual characteristic have been recently termed "superagers." This study aimed to explore the significance of imaging biomarkers acquired by ' $\mathrm{H}$-MRS to characterize superagers and to differentiate them from their normal-aging peers.
\end{abstract}

MATERIALS AND METHODS: Fifty-five patients older than 80 years of age were screened using a detailed neuropsychological protocol, and 25 participants, comprising 12 superagers and 13 age-matched controls, were statistically analyzed. We used state-of-theart $3 \mathrm{~T}^{\mathrm{l}} \mathrm{H}-\mathrm{MR}$ spectroscopy to quantify 18 neurochemicals in the posterior cingulate cortex of our subjects. All ${ }^{1} \mathrm{H}-\mathrm{MR}$ spectroscopy data were analyzed using LCModel. Results were further processed using 2 approaches to investigate the technique accuracy: 1) comparison of the average concentration of metabolites estimated with Cramer-Rao lower bounds $<20 \%$; and 2) calculation and comparison of the weighted means of metabolites' concentrations.

RESULTS: The main finding observed was a higher total $N$-acetyl aspartate concentration in superagers than in age-matched controls using both approaches $(P=.02$ and $P=.03$ for the weighted means), reflecting a positive association of total $N$-acetyl aspartate with higher cognitive performance.

CONCLUSIONS: 'H-MR spectroscopy emerges as a promising technique to unravel neurochemical mechanisms related to cognitive aging in vivo and providing a brain metabolic signature in superagers. This may contribute to monitoring future interventional therapies to avoid or postpone the pathologic processes of aging.

ABBREVIATIONS: CRLB = Cramer-Rao lower bounds; Glu = glutamate; GCP = glycerophosphocholine; NAAG = N-acetyl aspartylglutamate; PCho = phosphocholine; $\mathrm{PCr}=$ phosphocreatine

M ultifactorial neurobiologic mechanisms appear to underlie the complex phenomenon of superior cognitive performance in older adults. ${ }^{1}$ Subjects exhibiting this outstanding phenotype are newly described as "superagers" 2 and have been studied by imaging, through structural ${ }^{3}$ and functional MR imaging. ${ }^{4}$ To date, it is known that superagers show selective cortical preservation involving regions of the default mode and salience networks, which also exhibit strong functional connectivity. ${ }^{5}$ There is a

Received November 3, 2020; accepted after revision May 28, 2021.

From the Departments of Radiology and Oncology (L.L.d.G., C.d.C.L.) and Neurology (A.S.-N., N.C.M., M.S.Y., R.N.), and Division and Laboratory of Nuclear Medicine (A.M.C C.A.B.), Department of Radiology and Oncology, Hospital das Clinicas da Faculdade Medicina da Universidade de Sao Paulo, Sao Paulo, Brazil; The National Hospital of Neurology and Neurosurgery (L.L.d.G., M.W.-A., S.B.), University College London, London, UK; and Department of Biostatistics, Institute of Biosciences (M.H.T.), Universidade Estadual Paulista, Botucatu, Sao Paulo, Brazil.

L.L. de Goday and A. Studart-Neto share co-first authorship.

S. Bidas and C. da Costa Leite share co-senior authorship.

This work was funded by Fundação Amaro a Pesquisa do Estado de São Paulo (2.025.068). paucity of data, in particular generated by ${ }^{1} \mathrm{H}-\mathrm{MRS}$, related to the metabolic profile of the brains of superagers. ${ }^{6}$

Previous studies have reported the correlation between ${ }^{1} \mathrm{H}-\mathrm{MR}$ spectroscopy parameters of metabolite concentration with measures of intelligence, ${ }^{7-9}$ affect, ${ }^{10}$ creativity, ${ }^{11}$ and personality ${ }^{12}$ in cohorts of healthy human individuals, mostly younger adults. Such findings suggest that neurometabolites may be involved in healthy brain aging trajectories, such as those observed among superagers. Therefore, ${ }^{1} \mathrm{H}$-MR spectroscopy, which noninvasively probes several brain metabolites, can be used to provide information on

Please address correspondence to Laiz Laura de Godoy, MD, The National Hospita of Neurology and Neurosurgery, University College London, London, United Kingdom, Queen Square, Holborn, London WCIN 3G, UK; e-mail: laizlgodoy@gmail.com; @sbisdas

\footnotetext{
- Indicates open access to non-subscribers at www.ajnr.org

Indicates article with online supplemental data.

http://dx.doi.org/10.3174/ajnr.A7262
} 
biochemical pathways associated with the cognitive status of the aging brain. ${ }^{13}$

Physiologic aging changes involve specific cellular mechanisms, such as bioenergetics, oxidative stress, inflammation, cell membrane turnover, and endogenous neuroprotection revealed by neurochemicals in ${ }^{1} \mathrm{H}-\mathrm{MR}$ spectroscopy. ${ }^{14}$ Overall, the aging brain shows a reduced concentration of NAA and glutamate (Glu) and an increased concentration of choline (Cho) and myoinositol (mIns). ${ }^{6}$ Few studies showed a positive correlation between the NAA concentration and better memory performance in healthy older adults. ${ }^{6}$ Nevertheless, there are no studies to determine whether these age-related metabolite changes correlate with neuropsychological performance in superagers using agematched controls for comparison.

${ }^{1} \mathrm{H}-\mathrm{MR}$ spectroscopy under standardized conditions is necessary to obtain an accurate representation of the metabolic profile in vivo. First, the VOI must be placed in the least inhomogeneous area of gray or white matter. A high field strength (at least 3T) is needed to achieve better spectral resolution and a higher signalto-noise ratio for metabolites present in tissue at a much lower concentration than in water or those affected by J-coupling. ${ }^{15}$ Metabolite concentrations as relative ratios of creatine $(\mathrm{Cr})$ should be avoided in older adults ${ }^{16}$ because creatine seems to vary in the aging brain. ${ }^{17}$ Finally, optimal shimming methods and implementation of post hoc correction based on tissue and CSF segmentation within the VOI are mandatory. ${ }^{18}$

In the present study, we sought to investigate any relationship between brain metabolite concentrations obtained by ${ }^{1} \mathrm{H}-\mathrm{MR}$ spectroscopy with the late-life cognitive performance in a selected population of superagers and age-matched controls. We hypothesized that there is a different neurochemical signature between these 2 subject groups. Our results may be useful to address the resilience process of aging that underlies the superager's profile.

\section{MATERIALS AND METHODS Selection of Participants}

Initially, 55 participants (Online Supplemental Data) were screened from different centers in the city of Sao Paulo, Brazil, including the outpatient clinic of the Geriatrics Department of Hospital das Clinicas da Faculdade de Medicina da Universidade de Sao Paulo; the Open University Program for Senior Citizens at the School of Arts, Sciences and Humanities Universidade de Sao Paulo; and the Development Center for the Promotion of Healthy Aging. We also screened community elderly volunteers through social media and newspaper campaigns. Informed consent was obtained from each participant, and the research project was approved by the Ethics Committee of the University of Sao Paulo (No. 62047616.0.0000.0068). The study was designed and conducted according to the Declaration of Helsinki.

The inclusion criteria for the participants were the following: 1) 80 years of age or older; 2) education $\geq 4$ years; 3 ) Mini-Mental State Examination findings normal for their education status; ${ }^{19,20}$ 4) Functional Activity Questionnaire score $\leq 4, ;^{21}$ 5) Clinical Dementia Rating score equal to zero; and 6) the 15-question version of the Geriatric Depression Scale result of $\leq 5$.

The exclusion criteria included the following: 1) diagnosis of dementia or mild cognitive impairment according to the criteria of the National Institute on Aging and Alzheimer's Association; ${ }^{22,23}$ 2) diagnosis of a major psychiatric disorder by the Diagnostic and Statistical Manual of Mental Disorders, Fifth Edition; 3) a history of alcohol or psychoactive drug abuse; 4) current or previous diagnosis of diseases of the CNS (ie, stroke or seizure); 5) the presence of structural lesions in the CNS at image examination that could distort the brain parenchyma (ie, tumor or brain malformation); and 6) visual and/or auditory limitations that impair the performance of cognitive tests.

\section{Neurocognitive Screening}

The first assessment consisted of a semi-structured interview with the collection of sociodemographic data; cognitive assessment using the Mini-Mental State Examination, the Montreal Cognitive Assessment, and the Brief Cognitive Screening Battery; ${ }^{24}$ screening for depressive symptoms and anxiety using the Geriatric Depression Scale-15 and the Geriatric Anxiety Inventory, respectively; and a functional assessment with the Functional Activity Questionnaire score and the Clinical Dementia Rating.

Subsequently, the subjects who met the inclusion criteria underwent neuropsychological tests. The tests included Digit Span Forward and Backward, Trail-Making Tests A and B, category (animals) and letter verbal fluency tests, Rey-Osterrieth Complex Figure (copy and delayed recall), Logical Memory of the Wechsler Memory Scale, Rey Auditory Verbal Learning Test, the 60-item version of the Boston Naming Test, and the estimated intelligence quotient, which was measured with the Wechsler Adult Intelligence Scale, Third Edition. Those who performed equal or less than -1.5 SDs from average normative values adjusted by age and education for any cognitive test aforementioned were excluded.

\section{Healthy Older Adults Grouping}

Participants were separated into 2 groups: namely superagers and age-matched controls. Superagers were defined as the participants who presented a delayed recall score ( 30 minutes) of the Rey Auditory Verbal Learning Test, a measure of episodic memory, equal to or greater than average normative values for individuals $50-60$ years of age ( $\geq 9$ words), according to the criteria established by the Northwestern SuperAging Research Program. ${ }^{25}$ In addition, to fulfill this superager definition, they had to perform within or above $1 \mathrm{SD}$ of the average range for their age and demographics for cognitive function in the nonmemory domains tests, including the Digit Span Forward and Backward, the Boston Naming Test60, Trail-Making Tests A and B, the Rey-Osterrieth Complex Figure, and category (animals) and letter verbal fluency, according to the published normative values. ${ }^{26,27}$ The age-matched controls performed within $1 \mathrm{SD}$ of the average range for their age and demographics in memory and nonmemory domains, which means that they were average older adults according to their cognitive status.

\section{MR Imaging}

All MR imaging studies were performed on a 3T Signa PET/ MR scanner (GE Healthcare) using a multichannel receiver (8HRBRAIN) radiofrequency coil. First, 3D volumetric T1weighted images were acquired $(\mathrm{TR}=7.7 \mathrm{~ms}$; $\mathrm{TE}=3.1 \mathrm{~ms}$; $\mathrm{TI}=$ $600 \mathrm{~ms}$; in-plane resolution $=0.5 \times 0.5 \mathrm{~mm}{ }^{2}$ section thickness $=$ 


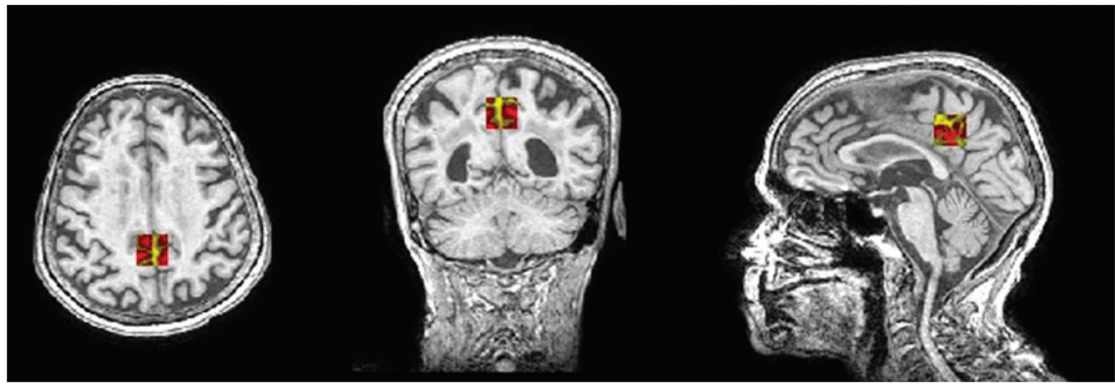

FIG 1. Voxel placement for ${ }^{~} \mathrm{H}-\mathrm{MR}$ spectroscopy on the posterior cingulate cortex. CSF (yellow) and gray and white matter (red).

$1 \mathrm{~mm}$, isotropic) and were used for ${ }^{1} \mathrm{H}-\mathrm{MR}$ spectroscopy voxel placement and to enable subsequent voxel segmentation to address the partial volume averaging. ${ }^{1} \mathrm{H}-\mathrm{MR}$ spectroscopy data were acquired with a single-voxel point-resolved spectroscopy sequence, with a bandwidth of $5000 \mathrm{~Hz}$. The standardized VOI measuring 20 $\times 20 \times 20 \mathrm{~mm}^{3}$ was always positioned on the posterior cingulate cortex as shown in Fig 1. ${ }^{1} \mathrm{H}-\mathrm{MR}$ spectroscopy preacquisition adjustments included high-order shimming (automatic and manual) within the selected region and optimization of water suppression. Water-suppressed spectra were then acquired with $\mathrm{TE}=35 \mathrm{~ms} ; \mathrm{TR}=1500 \mathrm{~ms} ; 4096$ complex points; and 128 transients. A reference spectrum without water suppression was also obtained.

\section{Data Analysis}

All spectroscopic data were analyzed using LCModel (Version 6.3-1; http://www.lcmodel.com/). ${ }^{28}$ Model spectra of 18 metabolites were included in the basis data set together with model spectra for macromolecules and lipids. ${ }^{29}$ Metabolite levels were estimated using internal water as a reference. A typical value for tissue water content in the gray matter of $43,300 \mathrm{mM}$ was applied. $^{30}$ The parameter was adjusted using T2 $\sim 80 \mathrm{~ms}$ for the major tissue water component, as previously reported. ${ }^{31}$ Metabolite levels were then corrected for partial volume of CSF in the ${ }^{1} \mathrm{H}-\mathrm{MR}$ spectroscopy VOI using the following correction factor (CSFcor), CSFcor $=1.0 /(1.0$-CSF fraction). The CSF fraction was calculated according to standard practice. ${ }^{32}$ Briefly, the steps were the following: 1) registration of the ${ }^{1} \mathrm{H}-\mathrm{MR}$ spectroscopy VOI to 3D T1-weighted images; 2) segmentation of the 3D T1-weighted volume using the SPM 8 software (http://www.fil. ion.ucl.ac.uk/spm/software/spm 12), ${ }^{33}$ and 3) use of segmentation results to determine the brain tissue and CSF fractions in the ${ }^{1} \mathrm{H}$ MR spectroscopy VOI.

Quality control of ${ }^{1} \mathrm{H}-\mathrm{MR}$ spectroscopy spectra was performed before the inclusion of LCModel results for further analysis. We used the following criteria: signal-to-noise ratio $>12$ (SNR obtained from LCModel analysis and defined as the maximum in a spectrum minus baseline over the Analysis Window to twice the root-mean-square of Residuals), and linewidths at full width at half maximum of $10 \mathrm{~Hz}$ (full width at half maximum obtained from LCModel analysis). The cutoff values for SNR and full width at half maximum were established experimentally as conservative thresholds to provide adequate quantitative assessment and consistent data quality across the 2 groups. ${ }^{34}$

\section{Statistical Analysis}

For metabolite concentrations, only those estimated values with relative Cramer-Rao lower bounds (CRLB) $<20 \%$ were retained in the statistical analysis. We also used an alternative approach based on the "weighted mean method." ${ }^{14}$

Descriptive statistics including mean, SD, standard error, median, and quartiles were generated for all study variables and groups. Distribution normality of the variables was assessed using the Shapiro-Wilks test. The means and medians among groups were compared using the 2 -sided $t$ test for independent samples and/or the Mann-Whitney $U$ test according to the normality assessment at $P<.05$. The comparison of means between groups was also performed using the weighted $t$ test (weighted linear model) at $P<.05$.

For the weighted mean approach, the weights (Wi) for each metabolite estimate were calculated as the following equation:

$$
w_{i}=\frac{1}{\left[C_{i}\left(\frac{R_{i}}{100}\right)\right]^{2}},
$$

where $C_{i}$ is the estimated concentration of a metabolite, and $R_{i}$, the corresponding CRLB (\%) measure. When the reliability is very low, CRLB\% > 80\% in the LCModel, the weight was defined as zero.

Then the weighted mean $(w M)$ and weighted SD $(w S D)$ were defined as

$$
w M=\frac{\sum_{i=1}^{N} w_{i} c_{i}}{\sum_{i=1}^{N} w_{i}}
$$

and

$$
w S D=\sqrt{\frac{\sum_{i=1}^{N} w_{i}\left(C_{i}-w M\right)^{2}}{\sum_{i=1}^{N} w_{i}}},
$$

where $i$ is the measurement index and $N$ is the number of measurements.

\section{Qualitative Examination}

In addition, a qualitative examination was performed on the basis of visual comparison of the spectral patterns shown by averaging spectra for each group (Fig 2). The difference spectrum was also calculated to highlight any differences among groups. The averaged spectra were calculated following normalization and spectral registration/alignment of individual within-group spectra using the FID-A tool (Matlab; MathWorks). ${ }^{35}$ 


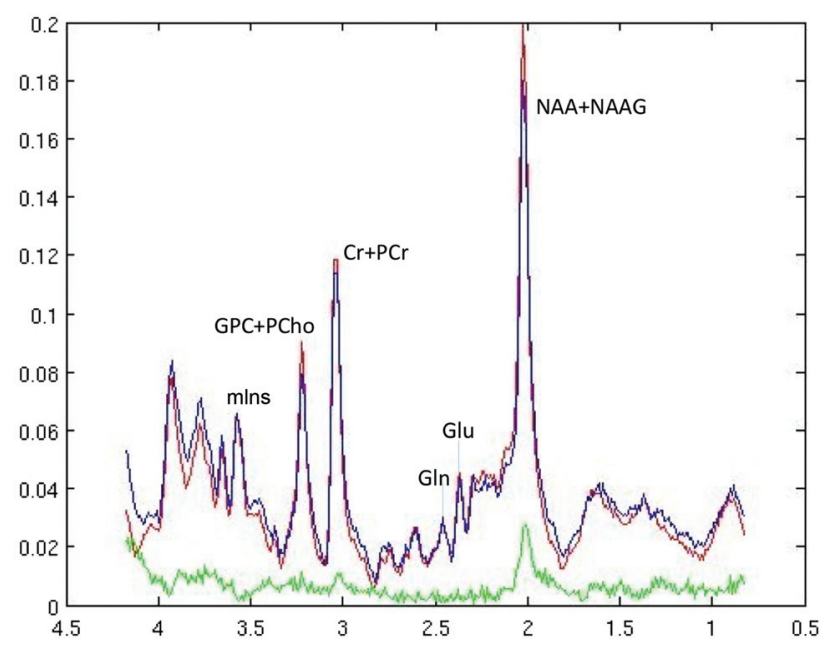

FIG 2. Averaged spectra for superagers (red), age-matched controls (blue), and the difference between groups (green). The most prominent difference is for NAA+NAAG (2.02 ppm), and there is a small difference for total $\mathrm{Cr}(3.03 \mathrm{ppm})$ and $\mathrm{mlns}(\sim 3.56 \mathrm{ppm})$ metabolites.
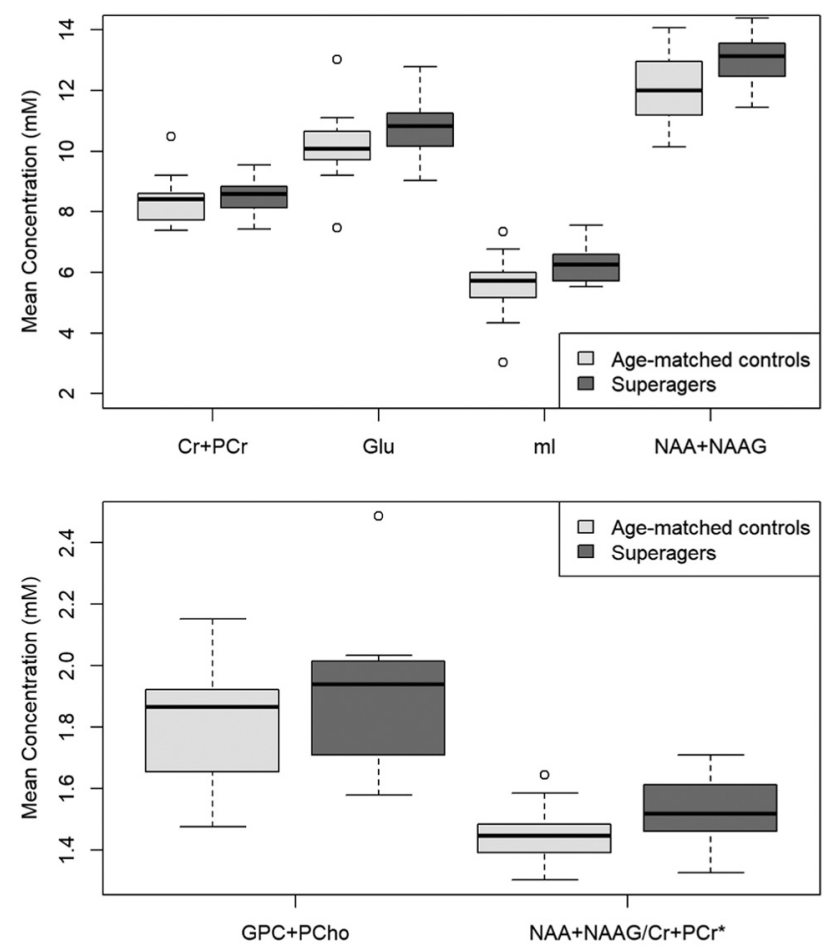

FIG 3. Boxplots showing metabolite concentration differences between superagers and age-matched controls. NAA+NAAG was statistically significantly more elevated in the posterior cingulate cortex of superagers than in age-matched controls $(P=.02)$, and mlns tended to be higher in superagers $(P=.06)$. $\mathrm{Cr}+\mathrm{PCr}$, Glu, $\mathrm{GCP}+\mathrm{PCho}$, and NAA+NAAG $/ \mathrm{Cr}+\mathrm{PCr}$ were not statistically significantly different across groups. The asterisk means do not consider the unit millimolar (mM) for the ratio NAA+NAAG/Cr+PCr.

\section{RESULTS}

\section{Demographics and Neuropsychological Performance of Participants}

Fourteen superagers and 15 age-matched controls were assessed through ${ }^{1} \mathrm{H}-\mathrm{MR}$ spectroscopy, but 2 superagers and 2 age-matched controls were excluded due to a low SNR. Twelve superagers and 13 age-matched controls were included in the statistical analyses (Online Supplemental Data). On the basis of the selection criteria, superagers and age-matched controls did not differ in terms of age, education, or sex distribution (Online Supplemental Data). Superagers had statistically significantly better performance compared with age-matched controls in the Montreal Cognitive Assessment and some episodic memory tests (delayed recall of the Brief Cognitive Screening Battery, delayed recall of the Rey Auditory Verbal Learning Test, and delayed recall of the Logical Memory II). See the Online Supplemental Data for demographic and neuropsychological testing information.

\section{'H-MR spectroscopy}

The location and size of the standardized voxel used for ${ }^{1} \mathrm{H}-\mathrm{MR}$ spectroscopy are shown in Fig 1. Averaged spectra illustrate the spectral quality consistently obtained in the posterior cingulate cortex (Fig 2). On average, the SNR in the superagers spectra was 22.7 (SD, 3.8) and 19.8 (SD, 4.2) in controls. In the superagers, cortex linewidths full width at half maximum were 5.22 (SD, 0.64) $\mathrm{Hz}$ compared with 5.09 (SD, 0.77) $\mathrm{Hz}$ in the agematched controls. Of 18 metabolites, 9 had CRLB\% $<20 \%$ (a frequently used inclusion criterion indicating acceptable fitting reliability; Online Supplemental Data). Four of them were sums of metabolites, including creatine + phosphocreatine $(\mathrm{Cr}+\mathrm{PCr})$; glycerophosphocholine+ phosphocholine (GCP+PCho); glutamate + glutamine $(\mathrm{Glu}+\mathrm{Gln})$ and $N$ - acetyl aspartate $+N$ acetylaspartyl glutamate (NAA+NAAG).

The results from the LCModel analysis were further processed using 2 approaches as aforementioned. First, only the concentrations of metabolites estimated with CRLB\% $<20 \%$ were considered for statistical analysis and comparisons; in the second, weighted means of the metabolite concentrations with CRLB\% < $20 \%$ were calculated and used to compare the 2 groups. The motivation for the second approach was to reflect the variable accuracy of fitted concentrations, providing rigor to the former findings. Superagers presented with statistically significantly higher NAA+NAAG concentrations than age-matched controls in both methods ( $P=.02$ and $P=.03$ for the weighted means). However, the ratio NAA+NAAG/Cr+PCr did not reach statistical significance $(P=.06)$ (Fig 3 and Online Supplemental Data).

mIns tended to be more increased in superagers than in average-age controls when considering metabolite concentration $(P=.06)$, but it was not statistically significant when analyzing the weighted mean $(P=.09)$. The remaining metabolites quantified reliably, including glycerophosphocholine + phosphocholine (GCP+PCho), Glu, and total creatine $(\mathrm{PCr}+\mathrm{Cr})$, did not demonstrate statistically significant differences between groups for both methods of measurement analysis (Fig 3 and Online Supplemental Data).

\section{Tissue Composition}

Superagers and age-matched controls did not differ significantly in the means of CSF and gray matter components in the VOIs; however, the groups showed statistically significant differences in the white matter content of the VOI composition, greater in superagers $(P=.04)$ (Online Supplemental Data). 


\section{DISCUSSION}

Our study highlighted and compared the metabolic differences in the posterior cingulate cortex of superagers and age-matched controls to find associations between superior memory performance and neurometabolites detected by ${ }^{1} \mathrm{H}-\mathrm{MR}$ spectroscopy. We evaluated cognitive-related differences independent of age showing higher levels of total NAA (NAA+NAAG) in superagers using 2 different methods of analysis, suggesting a positive association of total NAA with higher cognitive function.

Although some studies have investigated cognitive-related metabolic changes in the normal aging brain, ${ }^{6,36-41}$ to our knowledge, this is the first examination of metabolite concentrations in superagers. Our cohorts were made up of subjects older than 80 years of age because the concept of superior cognition as an index of resilience and resistance becomes more critical with age, ${ }^{42}$ and subjects between 60 and 80 years of age may be biased to obtain meaningful assertions about "youthful" memory performance. ${ }^{43,44}$ Furthermore, the reported literature of this age category is still limited.

We focused on the posterior cingulate cortex because it is one of the primary brain regions to display volume loss and reduced functional integrity during healthy aging and in neurodegenerative disorders. ${ }^{45,46}$ Compared with the hippocampal formation, the ${ }^{1} \mathrm{H}$-MR spectroscopy in the posterior cingulate cortex shows better homogenization of the magnetic field and fewer artifacts, providing more reliable and reproducible results. ${ }^{47}$ The observed differences in neurochemical concentrations in this region appeared to be not noticeably susceptible to differences in the VOI composition between the 2 groups. Even though there was a statistically significant difference in the white matter fraction (superagers $=0.15$; age-matched controls $=0.12$ ), the results of the VOI analysis of the posterior cingulate cortex were predominantly driven by the gray matter fraction (superagers $=0.65$; age-matched controls $=0.64) \quad$ (Online Supplemental Data) Moreover, the effect of the CSF content on metabolite concentration was considered during quantification, and no substantial differences were detected in the total tissue fraction content.

Total NAA is the sum of NAA and NAAG. The separation between NAA and NAAG using the $3 \mathrm{~T}{ }^{1} \mathrm{H}-\mathrm{MR}$ spectroscopy point-resolved spectroscopy sequence is inherently inaccurate; however, the sum of these metabolites can be estimated with good accuracy. NAA is a marker of neuronal and axonal function ${ }^{38}$ and may be implicated in mitochondrial activity, representing a potential source of neuronal metabolic efficiency. ${ }^{48}$ NAA can also be involved in myelin synthesis and maintenance. ${ }^{49}$

Previous findings in young adults have demonstrated that NAA levels are strongly associated with measures of intelligence, ${ }^{7-9}$ creativity, ${ }^{11}$ and, more recently, emotional constructs such as agency and flexibility. ${ }^{50}$ Superagers, by definition, have superior episodic memory performance, which is an important component of intelligence, according to more recent theoretic models. ${ }^{51}$ Therefore, our results support the relevance of the NAA levels in surrogate biomarkers of cognitive performance. Further studies are still necessary to investigate whether superagers may score higher on measures of creativity, emotion, and personality and whether such characteristics can be associated with the neurometabolic markers.
There is an agreement void in the literature regarding NAA levels in the normal-aging brain; however, studies using state-ofthe-art single-voxel ${ }^{1} \mathrm{H}-\mathrm{MR}$ spectroscopy showed an overall reduction in NAA, ${ }^{52-56}$ notably in the frontal lobes and hippocampus. ${ }^{6}$ Whole-brain ${ }^{1} \mathrm{H}-\mathrm{MR}$ spectroscopy studies also found decreased NAA concentrations with aging. ${ }^{57,58}$ In line with the literature, our age-matched controls presented with an expected reduction in the NAA concentration, further explaining some divergences among the previous aging studies in which the cognition status was not taken into account.

Even though different cognitive tasks and different VOIs were applied reporting cognitive-related metabolic changes in normal aging, our results in superagers are broadly in agreement with previous studies, ${ }^{36-41}$ which have shown a consistent positive association between NAA levels and cognitive performance. The previous studies have demonstrated higher NAA concentrations associated with improved performance on executive function tasks, digit-span tasks, composite processing speeds, memory tasks, and psychomotor processing speeds, supporting our findings in superagers.

Because gray matter loss is a component of aging, ${ }^{59}$ the reduction in NAA may be due to neuronal death or shrinkage. ${ }^{60}$ The agerelated reduction in synaptic density can also explain the decline in NAA concentration and underlie cognitive changes in older adults. ${ }^{61}$ It is also known that levels of NAA are reduced in neurodegenerative diseases ${ }^{62,63}$ such as Alzheimer disease, and its reduction has been associated with increased amyloid- $\beta$ markers in normal aging ${ }^{64}$ and in subjects with mild cognitive impairment. ${ }^{65}$ Thus, ${ }^{1} \mathrm{H}$ MR spectroscopy can be a noninvasive tool in vivo to diagnose, prognose, and monitor neurodegenerative disorders.

NAAG, a product of NAA, is a neurotransmitter that might be part of a compensatory neuroprotective mechanism through its actions on the presynaptic group II metabotropic glutamate receptors. ${ }^{66,67}$ Harris et al, ${ }^{14}$ in 2014 , showed significantly higher NAAG in both the hippocampus and cortex of older animals, suggesting a protective response to the constitutively elevated glucose in aged brains. Moreover, NAAG has been shown to protect neurons in vitro from cell death after exposure to high glucose, ${ }^{68,69}$ a metabolite that seems to play a key role in dementia pathology. $^{70}$

In a previous study reporting cognitive-related metabolic changes in healthy older adults, Kochunov et al, ${ }^{39}$ in 2010 , showed a positive relationship between higher $\mathrm{Cr}$ and $\mathrm{Cho}$ and better memory performance. Another study demonstrated a negative association between higher $\mathrm{Cho} / \mathrm{Cr}$ and $\mathrm{Cho} / \mathrm{mIns}$ concentrations and a composite score of global cognition. ${ }^{41}$ Our investigation did not find any differences in total Cho (GCP+PCho) in superagers compared with age-matched controls. Cho concentration seems to be elevated with age independent of cognitive status, notably in the posterior cingulate cortex and centrum semiovale, ${ }^{17,53,71}$ reflecting, most likely, increased cell membrane turnover and breakdown. ${ }^{14,56}$

Our results suggest a lack of association between cognitive performance and the concentration of total $\mathrm{Cr}$ demonstrated in normal aging. ${ }^{36}$ In addition, when considering total $\mathrm{Cr}$ as a denominator for the relative $\mathrm{NAA}+\mathrm{NAAG}$ concentration (NAA+NAAG/Cr+PCr), we could not detect statistically significant differences between superagers and age-matched controls, 
supporting previous findings that $\mathrm{Cr}$ changes are inconsistently associated with age. ${ }^{6}$ On the basis of this inconsistent concentration pattern, $\mathrm{Cr}$ must be avoided to determine metabolite ratios in elderly samples and can be misleading when considered as a biomarker in this population. ${ }^{16,36}$

Our analysis suggested a trend toward increased mIns in superagers compared with the age-matched controls. mIns has been described as a marker of glial proliferation. ${ }^{72,73}$ Nevertheless, this is questionable because brain tissue histopathology studies have not shown a statistically significant relationship between astrogliosis and mIns. ${ }^{74}$ Ultimately, mIns has been proposed to function as an osmolyte in the brain and is potentially implicated in brain cell signaling. ${ }^{75,76}$

Glu is a neurotransmitter involved in cognition, learning, and memory. ${ }^{56,77}$ Previous studies in dementia showed decreased Glu levels in mild cognitive impairment and notably in Alzheimer disease compared with healthy older adults. ${ }^{78,79}$ Other studies have shown Glu reduction with age. ${ }^{53,80}$ Among healthy older adults, when controlling for age, the literature lacks Glu examination for cognitive performance, and our study did not find differences in Glu concentration between the 2 groups. Nonetheless, more studies are still necessary to characterize the Glu role in cognition among the healthy elderly population.

The main strengths of our study were the use of a detailed and validated neuropsychological protocol to stratify older adults (older than 80 years of age) into superagers and age-matched controls and the implementation of standardized ${ }^{1} \mathrm{H}-\mathrm{MR}$ spectroscopy acquisition. ${ }^{17}$ Second, the VOI standardization and placement in the posterior cingulate cortex contribute to the generation of robust results that allow them to be easily validated in another setting. Finally, the implemented postprocessing methods, including measures of spectra quality and tissue/CSF segmentation to address the partial volume averaging in the ${ }^{1} \mathrm{H}-\mathrm{MR}$ spectroscopy measurements, enhanced the quality and reproducibility of our results. $^{81}$

Nevertheless, this study also presents some weaknesses. The published data concerning the prevalence of superagers in the global population are still insufficient ${ }^{82}$ and did not allow us to undertake a power sample analysis before study conduction. In previous studies using the same inclusion criteria, the sample size of superagers varied from $12^{2}$ to $56^{83}$ The examined metabolite concentrations were limited to those sampled in the posterior cingulate cortex; however, metabolite concentrations differ among distinct portions of the brain and between gray and white matter, ${ }^{84}$ possibly having an unpredictable impact on normal aging and the superagers' metabolic signatures. Also, no inferences regarding the impact of aging on several metabolite levels could be drawn. Future studies with whole-brain ${ }^{1} \mathrm{H}-\mathrm{MR}$ spectroscopy and control groups with younger volunteers would be useful to understand better metabolic profile changes during aging in different brain regions.

\section{CONCLUSIONS}

The present single-voxel ${ }^{1} \mathrm{H}-\mathrm{MR}$ spectroscopy study provides in vivo evidence that superior memory performance in late life is positively associated with total NAA in the posterior cingulate cortex. These findings indicate that higher total NAA can contribute to the resilience process of the conventional pathways of aging present in superagers. Expanding on the current results, future evidence accumulation will probably qualify ${ }^{1} \mathrm{H}-\mathrm{MR}$ spectroscopy as a diagnostic means for the quantification of neurochemical biomarkers in the aging population and as a prognostic tool including monitoring interventional therapies to preserve or enhance cognition in later life.

\section{ACKNOWLEDGMENTS}

We thank the participants and their families for their involvement and diligence and Hospital das Clinicas da Faculdade de Medicina da Universidade de Sao Paulo and The National Hospital of Neurology and Neurosurgery, University College London. We also thank Mrs Camila de Godoi Carneiro, MSc, for her technical support with data collection and anonymization, as well as data transfer across Institutions.

Disclosures: Marzena Wylezinska-Arridge-UNRELATED: Employment: National Hospital for Neurology and Neurosurgery. Carlos Buchpiguel-RELATED: Grant: Fundação Amaro a Pesquisa do Estado de São Paulo, Comments: Official Governamental Research Agency of São Paulo.* Ricardo Nitrini-UNRELATED: Employment: University of São Paulo Medical School; Grants/Grants Pending: Alzheimer's Association, Fundação Amaro a Pesquisa do Estado de São Paulo*; Payment for Lectures Including Service on Speakers Bureaus: One meeting prepared by Biogen. *Money paid to the institution.

\section{REFERENCES}

1. de Godoy LL, Alves CA, Saavedra JS, et al. Understanding brain resilience in superagers: a systematic review. Neuroradiology 2021;63:66383 CrossRef Medline

2. Harrison TM, Weintraub S, Mesulam MM, et al. Superior memory and higher cortical volumes in unusually successful cognitive aging. J Int Neuropsychol Soc 2012;18:1081-85 CrossRef Medline

3. Gefen T, Peterson M, Papastefan ST, et al. Morphometric and histologic substrates of cingulate integrity in elders with exceptional memory capacity. J Neurosci 2015;35:1781-91 CrossRef Medline

4. Wang X, Ren P, Baran TM, et al. Alzheimer's Disease Neuroimaging Initiative. Longitudinal functional brain mapping in supernormals. Cereb Cortex 2019;29:242-52 CrossRef Medline

5. Zhang J, Andreano JM, Dickerson BC, et al. Stronger functional connectivity in the default mode and salience networks is associated with youthful memory in superaging. Cereb Cortex 2020;30:72-84 CrossRef Medline

6. Cleeland C, Pipingas A, Scholey A, et al. Neurochemical changes in the aging brain: a systematic review. Neurosci Biobehav Rev 2019;98:30619 CrossRef Medline

7. Jung RE, Gasparovic C, Chavez RS, et al. Imaging intelligence with proton magnetic resonance spectroscopy. Intelligence 2009;37:19298 CrossRef Medline

8. Jung RE, Yeo RA, Chiulli SJ, et al. Myths of neuropsychology: intelligence, neurometabolism, and cognitive ability. Clin Neuropsychol 2000;14:535-45 CrossRef Medline

9. Jung RE, Brooks WM, Yeo RA, et al. Biochemical markers of intelligence: a proton MR spectroscopy study of normal human brain. Proc Bio Sci 1999;266:1375-79 CrossRef Medline

10. Jung RE, Yeo RA, Love TM, et al. Biochemical markers of mood: a proton magnetic resonance spectroscopy study of normal human brain. Biol Psychiatry 2002;51:224-29 CrossRef Medline

11. Jung RE, Gasparovic C, Chavez RS, et al. Biochemical support for the "Threshold" theory of creativity: a magnetic resonance spectroscopy study. J Neurosci 2009;29:5319-25 CrossRef Medline

12. Ryman SG, Gasparovic C, Bedrick EJ, et al. Brain biochemistry and personality: a magnetic resonance spectroscopy study. PLoS One 2011;6:e26758 CrossRef Medline 
13. Lee MR, Denic A, Hinton DJ, et al. Preclinical (1)H-MRS neurochemical profiling in neurological and psychiatric disorders. Bioanalysis 2012;4:1787-804 CrossRef Medline

14. Harris JL, Yeh HW, Swerdlow RH, et al. High-field proton magnetic resonance spectroscopy reveals metabolic effects of normal brain aging. Neurobiol Aging 2014;35:1686-94 CrossRef Medline

15. Schmitt F, Grosu D, Mohr C, et al. 3 Tesla MRI: successful results with higher field strengths. Radiologe 2004;44:31-47 CrossRef Medline

16. Jansen JF, Backes WH, Nicolay $\mathrm{K}$, et al. 1H MR spectroscopy of the brain: absolute quantification of metabolites. Radiology 2006;240:31832 CrossRef Medline

17. Chiu PW, Mak HK, Yau KK, et al. Metabolic changes in the anterior and posterior cingulate cortices of the normal aging brain: proton magnetic resonance spectroscopy study at 3T. Age (Dordr) 2014;36:251-64 CrossRef Medline

18. Oz G, Alger JR, Barker PB, et al. MRS Consensus Group. Clinical proton MR spectroscopy in central nervous system disorders. Radiology 2014;270:658-79 CrossRef Medline

19. Folstein MF, Folstein SE, McHugh PR. Mini-Mental State: a practical guide for grading the mental state of patients for the clinician. J Psych Res 1975;12:189-98 CrossRef Medline

20. Brucki S, Nitrini R, Caramelli P, et al. Suggestions for utilization of the mini-mental state examination in Brazil [in Portuguese]. Arq Neuropsiquiatr 2003;61:777-81 CrossRef Medline

21. Pfeffer RI, Kurosaki TT, Harrah CH Jr, et al. Measurement of functional activities in older adults in the community. J Gerontol 1982;37:323-29 CrossRef Medline

22. McKhann GM, Knopman DS, Chertkow H, et al. The diagnosis of dementia due to Alzheimer's disease: recommendations from the National Institute on Aging-Alzheimer's Association workgroups on diagnostic guidelines for Alzheimer's disease. Alzheimers Dement 2011;7:263-69 CrossRef Medline

23. Albert MS, DeKosky ST, Dickson D, et al. The diagnosis of mild cognitive impairment due to Alzheimer's disease: recommendations from the National Institute on Aging-Alzheimer's Association workgroups on diagnostic guidelines for Alzheimer's disease. Alzheimers Dement 2011;7:270-79 CrossRef Medline

24. Nitrini R, Caramelli P, Porto CS, et al. Brief cognitive battery in the diagnosis of mild Alzheimer's disease in subjects with medium and high levels of education. Dement Neuropsychol 2007;1:32-36 CrossRef Medline

25. Rogalski EJ, Gefen T, Shi J, et al. Youthful memory capacity in old brains: anatomic and genetic clues from the Northwestern SuperAging Project. J Cogn Neurosci 2013;25:29-36 CrossRef Medline

26. Heaton RK, Miller SW, Taylor MJ, et al. Revised comprehensive norms for an expanded Halstead-Reitan Battery: Demographically Adjusted Neuropsychological Norms For African American and Caucasian adults. 2004. http://www4.parinc.com/Products/Product. aspx?ProductID=RCNAAC. Accessed September 10, 2020

27. Shirk SD, Mitchell MB, Shaughnessy LW, et al. A web-based normative calculator for the Uniform Data Set (UDS) neuropsychological test battery. Alzheimers Res Ther 2011;3:32 CrossRef Medline

28. Provencher SW. Estimation of metabolite concentrations from localizedin vivo proton NMR spectra. Magn Reson Med 1993;30:672-79 CrossRef Medline

29. Seeger U, Klose U, Mader I, et al. Parameterized evaluation of macromolecules and lipids in proton MR spectroscopy of brain diseases. Magn Reson Med 2003;49:19-28 CrossRef Medline

30. Kreis R, Ernst T, Ross BD. Absolute quantitation of water and metabolites in the human brain, II: metabolite concentrations. $J$ Magn Reson B 1993;102:9-19 CrossRef

31. Ernst T, Kreis R, Ross BD. Absolute quantitation of water and metabolites in the human brain, I: compartments and water. $J$ Magn Reson B 1993;102:1-8 CrossRef

32. Edden RA, Puts NA, Harris AD, et al. Gannet: a batch-processing tool for the quantitative analysis of gamma-aminobutyric acid-edited MR spectroscopy spectra. J Magn Reson Imaging 2014;40:1445-52 CrossRef Medline
33. Friston KJ, Holmes AP, Worsley KJ, et al. Statistical parametric maps in functional imaging: a general linear approach. Hum Brain Mapp 1994;2:189-210 CrossRef

34. Pedrosa de Barros N, Slotboom J. Quality management in in vivo proton MRS. Anal Biochem 2017;529:98-116 CrossRef Medline

35. Simpson R, Devenyi GA, Jezzard P, et al. Advanced processing and simulation of MRS data using the FID appliance (FID-A): an open source, MATLAB-based toolkit. Magn Reson Med 2017;77:23-33 CrossRef Medline

36. Charlton RA, McIntyre DJO, Howe FA, et al. The relationship between white matter brain metabolites and cognition in normal aging: the GENIE study. Brain Res 2007;1164:108-16 CrossRef Medline

37. Driscoll I, Hamilton DA, Petropoulos H, et al. The aging hippocampus: cognitive, biochemical and structural findings. Cereb Cortex 2003;13:1344-51 CrossRef Medline

38. Ross AJ, Sachdev PS,Wen W, et al. Cognitive correlates of $1 \mathbf{H}$ MRS measures in the healthy elderly brain. Brain Res Bull 2005;66:9-16 CrossRef Medline

39. Kochunov P, Coyle T, Lancaster J, et al. Processing speed is correlated with cerebral health markers in the frontal lobes as quantified by neuroimaging. Neuroimage 2010;49:1190-99 CrossRef Medline

40. Erickson KI, Weinstein AM, Sutton BP, et al. Beyond vascularization: aerobic fitness is associated with $\mathrm{N}$-acetylaspartate and working memory. Brain Behav 2012;2:32-41 CrossRef Medline

41. Gomar JJ, Gordon ML, Dickinson D, et al. APOE genotype modulates proton magnetic resonance spectroscopy metabolites in the aging brain. Biol Psychiatry 2014;75:686-92 CrossRef Medline

42. Rogalski EJ. Don't forget: age is a relevant variable in defining SuperAgers. Alzheimers Dement (Amst) 2019;11:560-61 CrossRef Medline

43. Nyberg L, Lövdén M, Riklund $\mathrm{K}$, et al. Memory aging and brain maintenance. Trends Cogn Sci 2012;16:292-305 CrossRef Medline

44. Borelli WV, Carmona KC, Studart-Neto A, et al. Operationalized definition of older adults with high cognitive performance. Dement Neuropsychol 2018;12:221-27 CrossRef Medline

45. Minoshima S, Giordani B, Berent S, et al. Metabolic reduction in the posterior cingulate cortex in very early Alzheimer's disease. Ann Neurol 1997;42:85-94 CrossRef Medline

46. Lehmann M, Rohrer JD, Clarkson MJ, et al. Reduced cortical thickness in the posterior cingulate gyrus is characteristic of both typical and atypical Alzheimer's disease. J Alzheimers Dis 2010;20:58798 CrossRef Medline

47. Park EJ, Lyra KP, Lee HW, et al. Correlation between hippocampal volumes and proton magnetic resonance spectroscopy of the posterior cingulate gyrus and hippocampi in Alzheimer's disease. Dement Neuropsychol 2010;4:109-13 CrossRef Medline

48. Scavuzzo CJ, Moulton CJ, Larsen RJ. The use of magnetic resonance spectroscopy for assessing the effect of diet on cognition. Nutr Neurosci 2018;21:1-15 CrossRef Medline

49. Chakraborty G, Mekala P, Yahya D, et al. Intraneuronal N-acetylaspartate supplies acetyl groups for myelin lipid synthesis: evidence for myelin-associated aspartoacylase. J Neurochem 2001;78:736-45 CrossRef Medline

50. White TL, Gonsalves MA, Cohen RA, et al. The neurobiology of wellness: 1H-MRS correlates of agency, flexibility and neuroaffective reserves in healthy young adults. Neuroimage 2021;225:117509 CrossRef Medline

51. Jewsbury PA, Bowden SC, Duff K. The Cattell-Horn-Carroll Model of cognition for clinical assessment. J Psychoeduc Assess 2017;35:54767 CrossRef

52. Hädel S, Wirth C, Rapp M, et al. Effects of age and sex on the concentrations of glutamate and glutamine in the human brain. $J$ Magn Reson Imaging 2013;38:1480-87 CrossRef Medline

53. Marjańska M, Riley McCarten J, Hodges J, et al. Region-specific aging of the human brain as evidenced by neurochemical profiles measured noninvasively in the posterior cingulate cortex and the 
occipital lobe using $1 \mathrm{H}$ magnetic resonance spectroscopy at $7 \mathrm{~T}$. Neuroscience 2017;354:168-77 CrossRef Medline

54. Sailasuta N, Ernst T, Chang L. Regional variations and the effects of age and gender on glutamate concentrations in the human brain. Magnetic Resonance Imaging 2008;26:667-75 CrossRef Medline

55. Yang ZY, Yue Q, Xing HY, et al. A quantitative analysis of (1)H-MR spectroscopy at $3.0 \mathrm{~T}$ of three brain regions from childhood to middle age. $\mathrm{Br}$ J Radiol 2015;88:20140693 CrossRef Medline

56. Zahr NM, Mayer $\mathrm{D}$, Rohlfing $\mathrm{T}$, et al. In vivo glutamate measured with magnetic resonance spectroscopy: behavioral correlates in aging. Neurobiol Aging 2013;34:1265-76 CrossRef Medline

57. Eylers VV, Maudsley AA, Bronzlik P, et al. Detection of normal aging effects on human brain metabolite concentrations and microstructure with whole-brain MR spectroscopic imaging and quantitative MR imaging. AJNR Am J Neuroradiol 2016;37:447-54 CrossRef Medline

58. Ding, XQ, Maudsley, AA, Sabati, M, et al. Physiological neuronal decline in healthy aging human brain: an in vivo study with MRI and short echo-time whole-brain 1H MR spectroscopic imaging. Neuroimage 2016;137:45-51 CrossRef Medline

59. Drachman DA. Aging of the brain, entropy, and Alzheimer disease. Neurology 2006;67:1340-52 CrossRef Medline

60. Peters A, Morrison JH, Rosene DL, et al. Feature article: are neurons lost from the primate cerebral cortex during normal aging? Cereb Cortex 1998;8:295-300 CrossRef Medline

61. Woods DL, Wyma JM, Herron TJ, et al. The effects of aging, malingering, and traumatic brain injury on computerized trail-making test performance. PLoS One 2015;10:e124345 CrossRef Medline

62. Graff-Radford J, Kantarci K. Magnetic resonance spectroscopy in Alzheimer's disease. Neuropsychiatr Dis Treat 2013;9:687-96 CrossRef Medline

63. Coutinho A, Porto FH, Zampieri PF, et al. Analysis of the posterior cingulate cortex with [18 F] FDG-PET and NAA/mI in mild cognitive impairment and Alzheimer's disease: correlations and differences between the two methods. Dement Neuropsychol 2015;9:38593 CrossRef Medline

64. Nedelska Z, Przybelski SA, Lesnick TG, et al. 1H-MRS metabolites and rate of $\beta$-amyloid accumulation on serial PET in clinically normal adults. Neurology 2017;89:1391-99 CrossRef Medline

65. Voevodskaya O, Poulakis K, Sundgren P, et al. Swedish BioFINDER Study Group. Brain myoinositol as a potential marker of amyloidrelated pathology: a longitudinal study. Neurology 2019;92:e395405 CrossRef

66. Sanabria ER, Wozniak KM, Slusher BS, et al. GCP II (NAALADase) inhibition suppresses mossy fiber-CA3 synaptic neurotransmission by a presynaptic mechanism. J Neurophysiol 2004;91:182-93 CrossRef Medline

67. Zhong C, Zhao X, Van KC, et al. NAAG, peptidase inhibitor increases dialysate NAAG and reduces glutamate, aspartate and GABA levels in the dorsal hippocampus following fluid percussion injury in the rat. J Neurochem 2006;97:1015-25 CrossRef Medline

68. Berent-Spillson A, Robinson AM, Golovoy D, et al. Protection against glucose-induced neuronal death by NAAG and GCP II inhibition is regulated by mGluR3. J Neurochem 2004;89:90-99 CrossRef Medline
69. Berent-Spillson A, Russell JW. Metabotropic glutamate receptor 3 protects neurons from glucose-induced oxidative injury by increasing intracellular glutathione concentration. J Neurochem 2007;101:342-54 CrossRef Medline

70. Kuehn BM. In Alzheimer research, glucose metabolism moves to center stage. JAMA 2020;323:297-99 CrossRef Medline

71. Gruber S, Pinker K, Riederer F, et al. Metabolic changes in the normal ageing brain: consistent findings from short and long echo time proton spectroscopy. Eur J Radiol 2008;68:320-27 CrossRef Medline

72. David JP, Ghozali F, Fallet-Bianco C, et al. Glial reaction in the hippocampal formation is highly correlated with aging in human brain. Neurosci Lett 1997;235:53-56 CrossRef Medline

73. Sandhir R, Onyszchuk G, Berman NE. Exacerbated glial response in the aged mouse hippocampus following controlled cortical impact injury. Exp Neurol 2008;213:372-80 CrossRef Medline

74. Duarte JM, Do KQ, Gruetter R. Longitudinal neurochemical modifications in the aging mouse brain measured in vivo by $1 \mathrm{H}$ magnetic resonance spectroscopy. Neurobiol Aging 2014;35:1660-68 CrossRef Medline

75. Novotny EJ Jr, Fulbright RK, Pearl PL, et al. Magnetic resonance spectroscopy of neurotransmitters in human brain. Ann Neurol 2003;54(Suppl 6):S25-31 CrossRef Medline

76. Hoyer C, Gass N, Weber-Fahr W, et al. Advantages and challenges of small animal magnetic resonance imaging as a translational tool. Neuropsychobiology 2014;69:187-201 CrossRef Medline

77. Ramadan S, Lin A, Stanwell P. Glutamate and glutamine: a review of in vivo MRS in the human brain. NMR Biomed 2013;26:1630-46 CrossRef Medline

78. Zeydan B, Deelchand DK, Tosakulwong N, et al. Decreased glutamate levels in patients with amnestic mild cognitive impairment: an sLASER proton MR spectroscopy and PiB-PET study. $J$ Neuroimaging 2017;27:630-36 CrossRef Medline

79. Wong D, Atiya S, Fogarty J, et al. Reduced hippocampal glutamate and posterior cingulate $\mathrm{N}$-acetyl aspartate in mild cognitive impairment and Alzheimer's disease is associated with episodic memory performance and white matter integrity in the cingulum: a pilot study. J Alzheimers Dis 2020;73:1385-405 CrossRef Medline

80. Suri S, Emir U, Stagg CJ, et al. Effect of age and the APOE gene on metabolite concentrations in the posterior cingulate cortex. Neuroimage 2017;152:509-16 CrossRef Medline

81. Reyngoudt H, Claeys T, Vlerick L, et al. Age-related differences in metabolites in the posterior cingulate cortex and hippocampus of normal ageing brain: a 1H-MRS study. Eur J Radiol 2012;81:e22331 CrossRef

82. Kim BR, Kwon H, Chun MY, et al. White matter integrity is associated with the amount of physical activity in older adults with super-aging. Front Aging Neurosci 2020;12:549983 CrossRef Medline

83. Huentelman MJ, Piras IS, Siniard AL, et al. Associations of MAP2K3 gene variants with superior memory in SuperAgers. Front Aging Neurosci 2018;10:155 CrossRef Medline

84. Kreis R, Slotboom J, Hofmann L, et al. Integrated data acquisition and processing to determine metabolite contents, relaxation times, and macromolecule baseline in single examinations of individual subjects. Magn Reson Med 2005;54:761-68 CrossRef Medline 